\title{
Influence of Community-Based Dental Education on Practice Choice: Preliminary Data from East Carolina University
}

\author{
Sharon Gordon, Abigail C. Warren, Wanda G. Wright
}

Abstract: Maldistribution of the dental workforce contributes to poor access to oral health care. Community-based dental education (CBDE) may help to address this problem by using experiential learning to encourage new dentists to practice in underserved areas. The East Carolina University School of Dental Medicine (East Carolina University SoDM) employs a multifaceted strategy, including CBDE, to increase the number of dentists practicing in underserved areas of North Carolina. The aim of this study was to assess the influence of CBDE and other factors on practice choice among East Carolina University SoDM graduates. This cross-sectional study assessed practice intentions before and after a senior-year CBDE experience. Data were obtained for students in three graduating years from written student reflections and self-reported practice plans solicited at graduation. Of the total 156 students between 2015 and 2017 (52 each year), all students participated in at least one component of this evaluation: all students (100\%) completed required student reflections, and $148(95 \%)$ provided pre-graduation practice plans. Data were also obtained on alumni practice characteristics via a survey of recent graduates; 72 alumni (46\% response rate) participated in the alumni survey. The assessments found positive attitudes towards the CBDE program before and after participation, although areas for improvement relating to business management and financial viability were reported. The majority of alumni respondents $(67 \%)$ remained in the state to practice after graduation, with half reporting practicing in rural areas. For most alumni respondents $(>75 \%)$, debt, salary, benefits, type of patient population, and desire to own/run a business were important factors other than the CBDE program influencing their practice choice. Nearly half of them $(45.8 \%)$ rated desire to work in a public health setting as an important factor. This study provides preliminary evidence of the effectiveness of this educational model in retaining new dentists within the state to address the critical shortage of dentists in North Carolina.

Sharon Gordon is currently Dean, UConn School of Dental Medicine and was Associate Dean for Research and Chair, Department of Foundational Sciences, East Carolina University School of Dental Medicine at the time of this study; Abigail C. Warren is a dental student, East Carolina University School of Dental Medicine; and Wanda G. Wright is Assistant Professor, Department of Foundational Sciences, and Division Director of Dental Public Health, East Carolina University School of Dental Medicine. Direct correspondence to Dr. Sharon Gordon, UConn School of Dental Medicine, 263 Farmington Ave., MC 3915, Farmington, CT 06030; sgordon@uchc.edu.

Keywords: dental education, community-based dental education, educational methodology, oral health care for the underserved, access to health care, career choice, community health

Submitted for publication 8/31/18; accepted 2/12/19; first published online 5/27/19

doi: $10.21815 / J D E .019 .101$

A mong the barriers to access to oral health care, dental workforce distribution is a contributing factor, with fewer dentists practicing in rural or low-income settings and a resulting shortage of dentists in these communities. ${ }^{1-3}$ Consequently, patients in underserved areas are at increased risk for poor oral health., ${ }^{4,5}$

One strategy for improving dental workforce distribution focuses on community-based dental education (CBDE). CBDE is an educational model in which students receive training in extramural settings (e.g., community clinics or private practices) and is broadly supported in dental education. ${ }^{6-9}$ In the U.S., the majority of senior dental students participate in extramural clinical rotations of at least three weeks' duration. ${ }^{10,11}$ Data have shown that CBDE improves dental student competence, productivity, and confidence as well as exposes students to practice opportunities in underserved settings. ${ }^{12-17}$

Although one goal of CBDE is to encourage students to practice in underserved settings, results of studies examining the impact of CBDE on intended practice choice have been mixed. Some studies have shown a measurable effect of CBDE on practice plans and awareness or intent to care for vulnerable or underserved populations. ${ }^{18-27}$ In contrast, others have failed to detect such an impact on student practice choice or have highlighted the effects of other factors 
(e.g., debt) on practice choice. ${ }^{28-32}$ Further, one study reported that students' intended practice choice did not always accurately predict subsequent behavior. ${ }^{33}$ Together, these reports raise the question of whether CBDE is an effective strategy for improving dental workforce distribution. ${ }^{3}$

This question has particular relevance for the East Carolina University School of Dental Medicine (East Carolina University SoDM), a dental school developed in response to a critical lack of access to oral health care for the population of North Carolina. ${ }^{34,35}$ North Carolina has one of the lowest dentist-topopulation ratios in the nation, ${ }^{36,37}$ and the majority of counties in the state are considered Dental Health Professional Shortage Areas (DHPSAs). ${ }^{38,39}$ As part of its mission, the East Carolina University SoDM employs a multifaceted strategy modeled on that used by the East Carolina University School of Medicine ${ }^{40}$ to encourage its students to practice in North Carolina after graduation. This strategy focuses on admissions/ recruitment, scholarships, and didactic and experiential CBDE ${ }^{35,41}$ In addition, the low tuition at the East Carolina University SoDM versus other dental schools, enabled by a grant from the U.S. Health Resources and Services Administration (HRSA), helps to attract students whose priorities align with the school's mission. The specific goal of this broad strategy is to increase the number of dentists practicing in North Carolina DHPSAs.

For the East Carolina University School of Medicine, these strategies have led to a measurable impact on physician distribution in North Carolina. In $2016,81.8 \%$ of its graduates intended to practice in North Carolina after completing their medical training; the percentages of graduates planning to work primarily in underserved and rural areas were higher than those for other U.S. medical schools (32.3\% and $5.1 \%$ versus $23.1 \%$ and $1.1 \%$, respectively).$^{40}$ Furthermore, the percentage of East Carolina University School of Medicine 2016 graduates planning to work in a large city was lower than that for other U.S. medical schools (11.9\% versus $38.6 \%$, respectively).

The CBDE arm of the strategy for the School of Dental Medicine requires all students to participate in three eight-week rotations at Community ServiceLearning Centers (CSLCs) during their senior year. The CSLCs are East Carolina University SoDM clinics located across North Carolina, with seven of the eight CSLCs located in counties designated as a DHPSA..$^{38,42}$ When possible, at least one of a student's CSLC rotations is located in a county near that student's hometown. Like the overarching strategy as a whole, the intent of the CBDE experience is to encourage students to practice in underserved areas in North Carolina after graduation and thus improve the state's dentist-to-population ratio.

Although anecdotal reports indicate that some graduates are engaging in a "mission-aligned" form of practice, ${ }^{43}$ the distribution of East Carolina University SoDM graduates' practice choices remain to be documented. Therefore, the aim of this study was to assess the influence of CBDE and other factors on practice choice among East Carolina University SoDM graduates.

\section{Methods}

This study was approved by the East Carolina University and Medical Center Institutional Review Board (Protocol UMCIRB \#16-000779: Community Service-Learning and Its Impact on Graduates' Future Practice Choices and Care for the Underserved). This cross-sectional study assessed pre- and postgraduation practice intentions and attitudes towards CBDE and care for populations that are underserved. Data were obtained from three sources: 1) written student reflections from a required course in the East Carolina University SoDM curriculum, 2) selfreported practice plans solicited at graduation, and 3) practice characteristics reported via an alumni survey. The first source reflects attitudes before the CBDE experience, the second reflects plans after the CBDE experience but before entry into practice, and the third reflects activities after entry into practice. The study's target population included all graduates of the East Carolina University SoDM from the first graduating class in 2015 through 2017.

All students at the East Carolina University SoDM participate in the Community Oral Health Practice (COHP) course intended as preparatory for community-based practice upon graduation. The course spans all four years of the curriculum (Table 1). During the spring semester of their junior year prior to their senior rotations, students in the COHP course are asked to reflect upon the motivational statements from their dental school applications, in which they had explained their motivation for becoming a dentist. Students were prompted to answer specific questions relating to how their motivations had changed since admission; the prompts were designed to elicit a broad range of responses relating to student attitudes toward practice intent, the $\mathrm{CBDE}$ 


\section{Table 1. Modules for the Community Oral Health Practice course}

\begin{tabular}{|c|c|c|c|}
\hline Year & Term & Module Title & Brief Description of Learning \\
\hline 1 & Fall & $\begin{array}{l}\text { Introduction to the Evidence } \\
\text { Base for Oral Health }\end{array}$ & $\begin{array}{l}\text { Encounter the scientific literature and assess evidence regarding health, } \\
\text { disease, disparities, culture, treatments, and the ethical care of patients. }\end{array}$ \\
\hline 1 & Spring & $\begin{array}{l}\text { Applied Evidence Base for } \\
\text { Oral Health }\end{array}$ & $\begin{array}{l}\text { Efficiently access and critically analyze scientific information and place these } \\
\text { skills in the context of evidence-based practice. }\end{array}$ \\
\hline 1 & Summer & $\begin{array}{l}\text { Evaluation of the Evidence } \\
\text { Base for Oral Health }\end{array}$ & Critically examine a peer-reviewed article. \\
\hline 2 & Fall & $\begin{array}{l}\text { Introduction to Oral } \\
\text { Epidemiology }\end{array}$ & $\begin{array}{l}\text { Practice using methods to better understand, characterize, and promote health } \\
\text { at a population level and study the epidemiology of diseases affecting minority } \\
\text { and underserved populations. }\end{array}$ \\
\hline 2 & Spring & Dental Public Health & $\begin{array}{l}\text { Explore prevention of diseases at the population/community level and learn } \\
\text { how dental, medical, and public health care systems are structured and how } \\
\text { services are provided, with a focus on access to care. }\end{array}$ \\
\hline 2 & Summer & $\begin{array}{l}\text { Cross-Cultural } \\
\text { Communication }\end{array}$ & $\begin{array}{l}\text { Receive feedback on communication skills, motivational interviewing, the } \\
\text { health belief model, and methods of behavioral change. }\end{array}$ \\
\hline 3 & Fall & $\begin{array}{l}\text { Cultural Competence for } \\
\text { Oral Health Professionals: } \\
\text { Service-Learning }\end{array}$ & $\begin{array}{l}\text { Enhance the delivery of high-quality services to culturally and linguistically } \\
\text { diverse individuals and underserved communities. Explore the link between } \\
\text { literacy and health in the U.S. and how poor health literacy impacts access to } \\
\text { health information and quality health care services. Participate in a required } \\
\text { service-learning experience and a poverty simulation experience. }\end{array}$ \\
\hline 3 & Spring & $\begin{array}{l}\text { Applied Clinical } \\
\text { Epidemiology }\end{array}$ & $\begin{array}{l}\text { Working with faculty mentors, use clinical data to define a clinical problem, } \\
\text { pose a research question, extract relevant data, conduct basic statistics, and } \\
\text { present a final project. }\end{array}$ \\
\hline 4 & All terms & $\begin{array}{l}\text { Community Service- } \\
\text { Learning rotations with } \\
\text { reflections on diverse } \\
\text { populations, business of } \\
\text { dentistry, and ethics }\end{array}$ & $\begin{array}{l}\text { Spend three rotations in different CSLC locations providing care for patients } \\
\text { and living in the communities they serve. Through working in a real-world, } \\
\text { community-based care delivery system, develop skills in caring for vulnerable } \\
\text { populations, gain hands-on experience in managing a dental practice, engage } \\
\text { in community outreach, and participate in public health and leadership training. }\end{array}$ \\
\hline
\end{tabular}

CSLC=Community Service-Learning Center

Note: The Community Oral Health Practice (COHP) course prepares students to provide care for vulnerable populations (e.g., children, older adults, homeless individuals, victims of abuse or trauma, individuals with HIV/AIDS, disabilities, mental health, or substance-related issues, low-income, low-education, and racial and ethnic minorities). This integrated course prioritizes public health dentistry. All students are required to complete eight terms (approximately 220 clock hours) of the COHP course before beginning their experience in the CSLCs.

experience, and the East Carolina University SoDM mission to enhance access to oral health care across the state. Students considered any motivational changes and documented these reflections in written form within three months prior to engaging in any required community-based clinic rotations. We examined the written reflections to identify common themes before the CBDE experience.

Self-reported practice plans were solicited from senior East Carolina University SoDM students at the time of graduation (approximately three weeks after the conclusion of all required CBDE but before entry into practice). Information was collected via a paper form on student hometown, planned practice type, and planned practice location. For summarization purposes in this study, we classified hometowns and planned practice locations as rural or urban based on the North Carolina Rural Center (for North Carolina counties) and Federal Office of Rural Health Policy classification systems, with regional cities or suburban counties considered as urban. ${ }^{44,45}$

To assess practice characteristics and the impact of CBDE on practice choice and care for those who are underserved, an anonymous online survey instrument (www.qualtrics.com) was distributed to East Carolina University SoDM graduates in the target population. Surveys were completed after graduation and were not required for any curricular activities; alumni respondents received no financial compensation for completion of the survey. The window for completion of the survey was in 2017 after both graduation and entry into practice for all members of the target population. The survey instrument captured information in four categories: demographic characteristics (e.g., year of graduation, gender, race/ethnicity, hometown description); practice characteristics (e.g., practice location, practice type) and post-graduation volunteerism; opinions of 
the East Carolina University SoDM CBDE experience; and factors (other than CBDE) influencing practice choice (e.g., geographic location and type of practice). Opinions of the CBDE experience and factors influencing practice choice were also assessed.

We reviewed student reflections to identify recurring themes related to practice intent before exposure to extramural dental education. For the selfreported pre-graduation practice plans and alumni surveys, frequencies and distributions were used to summarize survey responses, as appropriate. For the factors influencing practice choice, ratings of important/very important and unimportant/not a factor were combined into overall categories of "important" and "unimportant," respectively, based on the clustering of responses at those opposite ends of the scale. Given the preliminary nature of this investigation, we generally present only frequency and distribution data. All statistical analyses were conducted using SPSS version 24 (IBM Corp., Armonk, NY, USA).

\section{Results}

The target population comprised 156 students who matriculated at the East Carolina University SoDM between 2015 and 2017 (52 each year). Of these, all students participated in at least one component of this evaluation: all students (100\%) completed required student reflections; 148 students (95\%) provided pre-graduation practice plans; and 72 alumni (46\%) participated in the alumni survey. The alumni survey response rate increased with graduation year (Table 2), such that the highest response rate $(58 \%$ for those who graduated in 2017) coincided with year of survey distribution.

Demographic characteristics for the graduating classes and alumni respondents are shown by year in Table 2. Overall, approximately half of the participants were women, and three-fourths (>75\%) were Caucasian. Demographic characteristics were generally similar across the graduating classes over the duration of the study. With the exception of a higher proportion of women among alumni respondents than graduating students in 2016 (75\% vs. $46 \%)$, the demographic composition of alumni respondents was representative of that of the graduating classes. The students were from 95 of the 100 counties in North Carolina (data not shown).

\section{Self-Reported Practice Characteristics}

Self-reported practice characteristics were assessed twice during the study: once before entry into practice (to assess practice plans) and once after entry into practice (to assess practice characteristics). Practice plans were collected from 148 seniors at the

Table 2. Demographics of respondents in graduating classes and alumni respondents

\begin{tabular}{|c|c|c|c|c|c|c|c|c|}
\hline \multirow[b]{2}{*}{ Characteristic } & \multicolumn{2}{|c|}{2015} & \multicolumn{2}{|c|}{2016} & \multicolumn{2}{|c|}{2017} & \multicolumn{2}{|c|}{ Total } \\
\hline & Students & Alumni & Students & Alumni & Students & Alumni & Students & Alumni \\
\hline Number (response rate) & $52(100 \%)$ & $12(23 \%)$ & $52(100 \%)$ & $24(46 \%)$ & $52(100 \%)$ & $30(58 \%)$ & $156(100 \%)$ & $72(46 \%)$ \\
\hline $\begin{array}{l}\text { Gender } \\
\text { Declined to respond } \\
\text { Men } \\
\text { Women }\end{array}$ & $\begin{array}{c}- \\
28(54 \%) \\
24(46 \%)\end{array}$ & $\begin{array}{l}- \\
5(42 \%) \\
7(58 \%)\end{array}$ & $\begin{array}{c}- \\
28(54 \%) \\
24(46 \%)\end{array}$ & $\begin{array}{c}- \\
6(25 \%) \\
18(75 \%)\end{array}$ & $\begin{array}{c}- \\
26(50 \%) \\
26(50 \%)\end{array}$ & $\begin{array}{l}- \\
16(53 \%) \\
14(47 \%)\end{array}$ & $\begin{array}{l}- \\
82(53 \%) \\
74(47 \%)\end{array}$ & $\begin{array}{c}6(8 \%) \\
27(38 \%) \\
39(54 \%)\end{array}$ \\
\hline $\begin{array}{l}\text { Ethnic identification } \\
\text { Declined to respond } \\
\text { African American } \\
\text { Asian } \\
\text { Caucasian } \\
\text { Hispanic } \\
\text { Other }\end{array}$ & $\begin{array}{c}- \\
5(10 \%) \\
8(15 \%) \\
38(73 \%) \\
1(2 \%) \\
0\end{array}$ & $\begin{array}{c}- \\
1(8 \%) \\
0 \\
11(92 \%) \\
0 \\
0\end{array}$ & $\begin{aligned} & - \\
2 & (4 \%) \\
2 & (4 \%) \\
45 & (86 \%) \\
1 & (2 \%) \\
& 2(4 \%)\end{aligned}$ & $\begin{array}{c}- \\
3(13 \%) \\
0 \\
21(88 \%) \\
0 \\
0\end{array}$ & $\begin{array}{c}- \\
9(17 \%) \\
5(10 \%) \\
35(67 \%) \\
3(6 \%) \\
0\end{array}$ & $\begin{array}{c}- \\
3(10 \%) \\
0 \\
24(80 \%) \\
3(10 \%) \\
0\end{array}$ & $\begin{array}{c}- \\
16(10 \%) \\
15(10 \%) \\
118(76 \%) \\
5(3 \%) \\
2(1 \%)\end{array}$ & $\begin{array}{c}6(8 \%) \\
7(15 \%) \\
0 \\
56(78 \%) \\
3(4 \%) \\
0\end{array}$ \\
\hline $\begin{array}{l}\text { Post-graduation volunteerism } \\
\text { Volunteered in the past year } \\
\text { Provided oral health education } \\
\text { Provided volunteer dental care }\end{array}$ & & $\begin{array}{l}12(100 \%) \\
12(100 \%) \\
12(100 \%)\end{array}$ & & $\begin{array}{c}24(100 \%) \\
18(75 \%) \\
24(100 \%)\end{array}$ & & $\begin{array}{l}30(100 \%) \\
25(83 \%) \\
30(100 \%)\end{array}$ & & $\begin{array}{l}72(100 \%) \\
55(76 \%) \\
72(100 \%)\end{array}$ \\
\hline
\end{tabular}


time of graduation (Table 3). Among these students, the most frequent plans were private practice (49\%) and residency (47\%). Consistent with the East Carolina University SoDM mission, almost three-quarters of the students $(72 \%)$ planned to practice in North Carolina after graduation. Approximately one-third $(32 \%)$ planned to practice in rural areas after graduation, with most of such students (34 of 48) being from rural hometowns. Practice plans were similar across the graduation classes.

Alumni practice characteristics were assessed with the alumni survey and were generally consistent with the graduating seniors' reported practice plans (Table 3). All alumni respondents currently were in either a private practice $(50 \%)$ or residency $(50 \%)$. Similarly, consistent with the reported practice plans, two-thirds of alumni respondents $(67 \%)$ practiced in North Carolina at the time of the survey, and half $(50 \%)$ practiced in rural counties. With the exception of wide variation in rural practice rates (from zero to $75 \%$ ), practice characteristics were similar across the graduation classes.

Consistent with the mission of the East Carolina University SoDM to recruit students with a strong sense of civic responsibility and commitment to community service, all alumni respondents reported having engaged in post-graduation volunteerism (including providing dental care) in the past year (Table 2). Similarly, a large majority of alumni respondents ( $75 \%$ to $100 \%$ across graduating classes) had provided oral health education in a volunteer capacity.

\section{Attitudes About CBDE}

Attitudes regarding the CBDE experience were assessed twice during the study: once before starting the CBDE experience, and once after entry into practice. Pre-rotation attitudes about the CBDE experience were assessed via student reflections completed as part of the assigned coursework. Because these written reflections were a required component of the curriculum, all students in the target population participated in this component of the study. Selected representative statements are shown in Table 4. Overall, the reflections confirmed that students entered the CBDE experience with high expectations consistent with their motivations for applying to dental school. Most students remained very oriented to the

Table 3. Self-reported practice characteristics (graduating classes and alumni respondents)

\begin{tabular}{|c|c|c|c|c|c|c|c|c|}
\hline \multirow[b]{2}{*}{ Characteristic } & \multicolumn{2}{|c|}{2015} & \multicolumn{2}{|c|}{2016} & \multicolumn{2}{|c|}{2017} & \multicolumn{2}{|c|}{ Total } \\
\hline & $\begin{array}{c}\text { Graduating } \\
\text { Class } \\
N=50\end{array}$ & $\begin{array}{c}\text { Alumni } \\
\text { Respondents } \\
\mathrm{N}=12\end{array}$ & $\begin{array}{c}\text { Graduating } \\
\text { Class } \\
\mathrm{N}=51\end{array}$ & $\begin{array}{c}\text { Alumni } \\
\text { Respondents } \\
\mathrm{N}=24\end{array}$ & $\begin{array}{c}\text { Graduating } \\
\text { Class } \\
N=47\end{array}$ & $\begin{array}{c}\text { Alumni } \\
\text { Respondents } \\
\mathrm{N}=30\end{array}$ & $\begin{array}{c}\text { Graduating } \\
\text { Classes } \\
\mathrm{N}=148\end{array}$ & $\begin{array}{c}\text { Alumni } \\
\text { Respondents } \\
\mathrm{N}=66\end{array}$ \\
\hline \multicolumn{9}{|l|}{ Practice type } \\
\hline Private practice & $24(48 \%)$ & $12(100 \%)$ & $26(51 \%)$ & $6(25 \%)$ & $22(47 \%)$ & $15(50 \%)$ & $72(49 \%)$ & $33(50 \%)$ \\
\hline Residency & $24(48 \%)$ & 0 & $23(45 \%)$ & $18(75 \%)$ & $22(47 \%)$ & $15(50 \%)$ & $69(47 \%)$ & $33(50 \%)$ \\
\hline Community & $1(2 \%)$ & 0 & $1(2 \%)$ & 0 & $2(4 \%)$ & 0 & $4(3 \%)$ & 0 \\
\hline Other & $1(2 \%)$ & 0 & $1(2 \%)$ & 0 & $1(2 \%)$ & 0 & $3(2 \%)$ & 0 \\
\hline \multicolumn{9}{|l|}{$\begin{array}{l}\text { Practice location: } \\
\text { county type }\end{array}$} \\
\hline Rural & $15(30 \%)$ & 0 & $21(41 \%)$ & $18(75 \%)$ & $12(26 \%)$ & $15(50 \%)$ & $48(32 \%)$ & $33(50 \%)$ \\
\hline Rural hometown & $11(22 \%)$ & na & $15(29 \%)$ & na & $8(17 \%)$ & na & $34(23 \%)$ & na \\
\hline Urban hometown & $4(8 \%)$ & na & $6(12 \%)$ & na & $4(9 \%)$ & na & $14(9 \%)$ & na \\
\hline Urban & $35(70 \%)$ & $12(100 \%)$ & $30(59 \%)$ & $6(25 \%)$ & $35(74 \%)$ & $15(50 \%)$ & $100(68 \%)$ & $33(50 \%)$ \\
\hline Rural hometown & $13(26 \%)$ & na & $14(27 \%)$ & na & $13(28 \%)$ & na & $40(27 \%)$ & na \\
\hline Urban hometown & $22(44 \%)$ & na & $16(31 \%)$ & na & $22(47 \%)$ & na & $60(41 \%)$ & na \\
\hline \multicolumn{9}{|l|}{ State of practice } \\
\hline North Carolina & $36(72 \%)$ & $12(100 \%)$ & $39(76 \%)$ & $12(50 \%)$ & $32(68 \%)$ & $20(67 \%)$ & $107(72 \%)$ & $44(67 \%)$ \\
\hline Rural hometown & $19(38 \%)$ & na & $22(43 \%)$ & na & $16(34 \%)$ & na & 57 (39\%) & na \\
\hline Urban hometown & $17(34 \%)$ & na & $17(33 \%)$ & na & $16(34 \%)$ & na & $50(34 \%)$ & na \\
\hline Other state & $14(28 \%)$ & 0 & $12(24 \%)$ & $12(50 \%)$ & $15(32 \%)$ & $10(33 \%)$ & $41(28 \%)$ & $22(33 \%)$ \\
\hline Rural hometown & $5(10 \%)$ & na & $7(14 \%)$ & na & $5(11 \%)$ & na & $17(11 \%)$ & na \\
\hline Urban hometown & $9(18 \%)$ & na & $5(10 \%)$ & na & $10(21 \%)$ & na & $24(16 \%)$ & na \\
\hline
\end{tabular}

na=not available (hometown was not assessed in the alumni survey)

Note: Data in the "Graduating Class" columns were obtained from seniors at the time of graduation and reflect practice plans; data in the "Alumni Respondents" columns were obtained from the survey and reflect actual practice characteristics. Percentages may not total $100 \%$ due to rounding. Data from six alumni who returned the survey but declined to provide demographic information are not included in the "Alumni Respondents" columns. Under "Practice type," "Other" included military service, academics, corporate, and hospital. 
Table 4. Pre-rotation attitudes about community-based dental education: selected comments from student reflections

Prompt Topic

How have you or your

motivations for pursuing this

career changed since you wrote

your admissions statement?

How will you be perceived in the community during your CSLC rotation?

Have your ideas about community and civic involvement and your professional or civic identity changed since you wrote your admissions statement?

How will the experience in the community further your understanding of comprehensive dental medicine?

Comment

"My passion for dentistry has also increased since I wrote my admissions statement. It has been reinforced that this is a good profession that fits my personality and talents."

"I strive with more determination than I did prior to dental school. My ambitions still include giving back to my community, supporting my family, volunteering in dental clinics, participation in dental research."

"I believe they will recognize that we are there to learn and provide them with a service at very low financial cost."

"Initially, I believe we will be perceived as doctors and higher up on the totem pole than the community members. As we become more acclimated to the individual CSLC environments and communities, I believe and hope the community members will see that we are caring and humble individuals who want to improve the health of all the underserved."

"My ideas about the community and civic involvement have not changed much."

"My ideas about community and civic involvement have changed to be more ambitious. . . . I also want to integrate my own ideas into my community. . . . I think my presence and actions in the CSLC community will provide me with the characteristics to be adventurous and vibrant in a new community to share the knowledge I have about dental and overall health care."

"I think the CSLCs will offer a good environment for us to learn how to treat patients in more of a real-world setting. . . . I also expect to see different needs in each different CSLC that reflects their community."

"I think the experience in CSLCs will further my understanding on how to approach new communities who are not exposed to dental care and education. It will also benefit me to understand what the community expects of me outside of dental care, including overall health and community improvement."

"I absolutely do not want to go to [CSLC name]. [Town] is a dangerous community (most dangerous in the state, according to some studies), and I try to take as few risks as possible with my personal safety."

CSLC=community service-learning center

Note: In the bottom comment, the name of the CSLC and the nearby community were redacted to preserve anonymity.

East Carolina University SoDM mission of enhancing access to oral health care across the state and showed positive attitudes about the CSLC rotations. However, a minority of students expressed apprehension about the rotations by, for example, expressing reluctance to rotate at specific CSLCs.

After entry into practice, alumni respondents reported their attitudes regarding the CBDE experience with Likert scale items on the survey (Table 5). Attitudes were generally consistent with the positive expectations of the CBDE experience expressed in the course reflections. A large majority of alumni respondents $(92 \%)$ reported positive attitudes about the rotations, and similar high percentages $(>90 \%)$ agreed they felt prepared to be community leaders, to care for those who are underserved, and to use clinical skills in dental practice after the rotations. Over 90\% agreed that the CBDE program had provided ample opportunity to reflect on their experiences. Most $(>60 \%)$ agreed or strongly agreed that they felt prepared to understand clinical medicine in the primary care setting and to explore career options after the CBDE experience.
However, alumni responses were less positive regarding preparation for financial and practice management (business-related skills such as billing and receivables, communication, reimbursement from different types of payers, staffing/resourcing). Half of them $(50 \%)$ did not agree that the CBDE experience had prepared them to understand the financial aspects of running a dental practice, and 39\% said they did not feel prepared for practice management.

\section{Other Influences on Practice Choice}

Perceived factors other than CBDE that could influence practice choice were included on the survey. At least three-fourths of the respondents $(>75 \%)$ reported that debt, salary, benefits, type of patient population, and desire to own/run a business were important or very important factors influencing their practice choice (Table 6). Only $45.8 \%$ rated desire to work in a public health setting as important; none rated this factor as "very important." This item was the only factor that was not a statistically significant factor influencing practice choice. 
Table 5. Post-rotation attitudes about community-based dental education (CBDE), by number and percentage of alumni respondents by graduation class and total

\begin{tabular}{|c|c|c|c|c|}
\hline Attitude & $\begin{array}{l}2015 \\
\mathrm{~N}=12\end{array}$ & $\begin{array}{l}2016 \\
N=24\end{array}$ & $\begin{array}{l}2017 \\
N=30\end{array}$ & $\begin{array}{c}\text { Total } \\
\mathrm{N}=72\end{array}$ \\
\hline \multicolumn{5}{|c|}{ The CSLC rotations were a positive experience. } \\
\hline Strongly agree & $12(100 \%)$ & $12(50 \%)$ & $20(67 \%)$ & $44(61 \%)$ \\
\hline Agree & 0 & $12(50 \%)$ & $10(33 \%)$ & $22(31 \%)$ \\
\hline Neutral & 0 & 0 & 0 & $6(8 \%)$ \\
\hline \multicolumn{5}{|l|}{ I feel prepared to: } \\
\hline \multicolumn{5}{|c|}{ Be a community leader } \\
\hline Strongly agree & $12(100 \%)$ & $18(75 \%)$ & $25(83 \%)$ & $55(76 \%)$ \\
\hline Agree & 0 & $6(25 \%)$ & $5(17 \%)$ & $11(15 \%)$ \\
\hline Neutral & 0 & 0 & 0 & $6(8 \%)$ \\
\hline \multicolumn{5}{|c|}{ Provide oral health services for the underserved } \\
\hline Strongly agree & $12(100 \%)$ & $12(50 \%)$ & $20(67 \%)$ & $44(61 \%)$ \\
\hline Agree & 0 & $12(50 \%)$ & $10(33 \%)$ & $22(30 \%)$ \\
\hline Neutral & 0 & 0 & 0 & $6(8 \%)$ \\
\hline \multicolumn{5}{|c|}{ Use clinical dental skills } \\
\hline Strongly agree & $12(100 \%)$ & $12(50 \%)$ & $20(67 \%)$ & $44(61 \%)$ \\
\hline Agree & 0 & $12(50 \%)$ & $10(33 \%)$ & $22(31 \%)$ \\
\hline Neutral & 0 & 0 & 0 & $6(8 \%)$ \\
\hline \multicolumn{5}{|c|}{ Understand clinical medicine in the primary care setting } \\
\hline Strongly agree & $6(50 \%)$ & 0 & $5(17 \%)$ & $11(15 \%)$ \\
\hline Agree & $6(50 \%)$ & $18(75 \%)$ & $20(67 \%)$ & $44(61 \%)$ \\
\hline Neutral & 0 & $6(25 \%)$ & $5(17 \%)$ & $17(24 \%)$ \\
\hline \multicolumn{5}{|l|}{ Explore career options } \\
\hline Agree & $12(100 \%)$ & $12(50 \%)$ & $20(67 \%)$ & $44(61 \%)$ \\
\hline Neutral & 0 & $12(50 \%)$ & $10(33 \%)$ & $28(39 \%)$ \\
\hline \multicolumn{5}{|c|}{ Be financially viable in a dental practice } \\
\hline Agree & $12(100 \%)$ & $6(25 \%)$ & $15(50 \%)$ & $33(46 \%)$ \\
\hline Neutral & 0 & $12(50 \%)$ & $10(33 \%)$ & $22(31 \%)$ \\
\hline Disagree & 0 & $6(25 \%)$ & $5(17 \%)$ & $17(24 \%)$ \\
\hline \multicolumn{5}{|c|}{ Engage in practice management } \\
\hline Strongly agree & $6(50 \%)$ & 0 & $5(17 \%)$ & $11(15 \%)$ \\
\hline Agree & $6(50 \%)$ & $12(50 \%)$ & $15(50 \%)$ & $33(46 \%)$ \\
\hline Neutral & 0 & $12(50 \%)$ & $10(33 \%)$ & $22(31 \%)$ \\
\hline Strongly disagree & 0 & 0 & 0 & $6(8 \%)$ \\
\hline \multicolumn{5}{|c|}{ I had ample time to critically reflect on my CBDE learning. } \\
\hline Strongly agree & $6(50 \%)$ & 0 & $5(17 \%)$ & $11(15 \%)$ \\
\hline Agree & $6(50 \%)$ & $24(100 \%)$ & $25(83 \%)$ & $55(76 \%)$ \\
\hline Neutral & 0 & 0 & 0 & $6(8 \%)$ \\
\hline
\end{tabular}

CSLC=community service-learning center

Note: The Total column includes data from six alumni who returned the alumni survey but declined to provide demographic information so their year of graduation was unknown. These alumni are therefore not included in the graduation year columns. Response options for each survey item were strongly agree, agree, neutral, disagree, and strongly disagree, but options not selected by any respondents are not shown.

Given the increasing focus on the burden of student debt, ${ }^{46}$ we further examined whether year of graduation affected the reported influence of debt on practice choice. At least three-quarters of alumni respondents $(\geq 75 \%)$ in subgroups based on year of graduation rated debt as an important influence on their practice choice (Table 6). Given the small sample size available to date, effects of other demographic variables on the influence of debt on practice choice were not assessed.

\section{Discussion}

These preliminary results provide insight into the influence of the CBDE portion of the curriculum on our graduates' practice choices proximal to graduation and provide a benchmark for future comparisons of practice patterns. Consistent with the East Carolina University SoDM mission to provide access to oral health care in the state, our findings showed 


\begin{tabular}{|c|c|c|}
\hline Factor & Important & Unimportant \\
\hline Debt $^{\mathrm{a}}$ & $55(76.4 \%)$ & $17(23.6 \%)^{b}$ \\
\hline \multicolumn{3}{|l|}{ Debt by year of graduation ${ }^{c}$} \\
\hline $2015, M=12$ & $12(100 \%)$ & 0 \\
\hline $2016, M=24$ & $18(75 \%)$ & $6(25 \%)$ \\
\hline $2017, M=30$ & $25(83.3 \%)$ & $5(16.7 \%)$ \\
\hline Salary & $66(91.7 \%)$ & $6(8.3 \%)$ \\
\hline Benefits $^{\mathrm{a}}$ & $55(76.4 \%)$ & $17(23.6 \%)$ \\
\hline Type of patient population ${ }^{\mathrm{a}}$ & $66(91.7 \%)$ & $6(8.3 \%)$ \\
\hline Desire to run/own business ${ }^{a}$ & $55(76.4 \%)$ & $17(23.6 \%)$ \\
\hline Desire to work in public health setting ${ }^{a}$ & $44(45.8 \%)$ & $39(54.2 \%)$ \\
\hline \multicolumn{3}{|c|}{$\begin{array}{l}\text { Note: The "Important" column combines responses of very important and important. The } \\
\text { "Unimportant" column combines responses of unimportant and not a factor. }\end{array}$} \\
\hline \multicolumn{3}{|c|}{$\begin{array}{l}\text { aPercentages calculated as } \mathrm{n} / \mathrm{N} \text {. } \\
\text { bIncludes data for six alumni who declined to provide demographic information. } \\
\text { cPercentages calculated as } \mathrm{n} / \mathrm{M} \text {. }\end{array}$} \\
\hline
\end{tabular}

that the majority of our graduates planned to and do practice in North Carolina, with a substantial proportion of them practicing in rural areas. Combined with positive student and alumni assessments of the CBDE program, these data support the effectiveness of one component of East Carolina University SoDM's educational model in influencing the distribution of new dentists in North Carolina.

Two major findings of our study - the high in-state retention and rural practice rates - are best considered in the context of data from other U.S. dental schools. Our in-state retention rate ( $72 \%$ planned, $67 \%$ actual) is consistent with the high rates at other public dental schools that receive state funding to subsidize the cost of dental education. ${ }^{3}$ However, the percentage of East Carolina University SoDM graduates practicing in rural areas $(32 \%$ planned, $50 \%$ actual) is notably higher than those of most other dental schools, which typically report less than $20 \%$ of graduates practicing in rural areas. The percentage of our graduates practicing in rural areas is comparable to or higher than those from schools in small, rural states that tend to produce graduates more likely to practice in rural areas.

These findings are consistent with data from the East Carolina University School of Medicine, ${ }^{40}$ on which the mission and admission and recruitment strategies of the East Carolina University SoDM were modeled. Like the SoDM, the East Carolina University School of Medicine employs a multifaceted approach to increase the supply of primary care physicians serving in North Carolina. In addition, both schools offer comparatively low tuitions that reduce both student debt and the impact of debt on practice choice.
Given the similarities in mission and educational strategy between the medical and dental schools, these successes are encouraging and predict continuing progress toward the East Carolina University mission to care for populations that are underserved.

Our findings are also consistent with those from multiple other dental schools that have employed CBDE as a method for influencing dental practice choice. For example, the A.T. Still University (ATSU) Arizona School of Dentistry \& Oral Health similarly tailors its admissions strategies and curricular content to encourage graduates to serve populations in need and includes an intensive CBDE component in its curriculum. ${ }^{47} \mathrm{At}$ the ATSU, the CBDE rotation experience has been found to prepare most students $(65 \%)$ for a career in dentistry and has affected practice choice for the majority ( $85 \%$ ) of graduates. ${ }^{22} \mathrm{In}$ particular, $53 \%, 32 \%$, and $32 \%$ of the school's graduates in 2007, 2008, and 2009 who entered practice chose a community-based or public health setting. ${ }^{47}$ Likewise, participation in CBDE experiences at the University of Michigan and West Virginia University positively affected student interest in practicing at community-based dental clinics and rural areas..$^{21,27} \mathrm{At}$ the University of Michigan, when the CBDE rotations increased from three-five weeks up to eight weeks, the percentage of students who chose a community-based dental clinic as their preferred practice location increased from $5.6 \%$ to $11.8 \%$ in 2009 and then to $16.5 \%$ in the following year. ${ }^{21}$ At West Virginia University, $25 \%$ of the students who had not expected to have a rural practice prior to participating in a rural clinic rotation subsequently chose to practice in a rural area. ${ }^{27}$ The consistency of our results with these findings 
suggests that CBDE programs, particularly those of extended duration, may provide a feasible method for increasing the number of dentists practicing in dentally underserved areas. Nevertheless, given the small sample size of our study and thus relatively low percentage of our graduates planning to or actually working in community-based positions, additional data are needed to determine the practical effects of our CBDE program on the care of individuals from underserved populations.

In contrast, findings from three other studies do not completely affirm our results..$^{28-30}$ However, the methodology used in those studies was not directly comparable to ours: their programs compared perceptions from current dental students or graduates who participated in two different types of programs (traditional curriculum versus community-based rotations) and assessed willingness to treat underserved populations. Thus, the exposure and outcomes reported are not comparable to those presented in our study.

A secondary goal of our study was to assess student and alumni experiences at the East Carolina University SoDM to identify shortcomings of the CBDE program. Previous research has found that a well-defined structure and the opportunity to reflect on experiences are important factors for maximizing the impact of CBDE. ${ }^{26,48-50}$ Our assessments showed high satisfaction with the CBDE program structure, and students reported ample opportunity to reflect upon their experiences. However, our study revealed areas for improvement relating to the business aspects of managing a dental practice and maintaining financial viability. Given the practice setting and patient mix they will encounter, we note the specific need for better preparation to manage reimbursement from a variety of sources including Medicaid. Although the CBDE program at East Carolina University SoDM was originally designed to allow students to gain experience in the CSLC business offices while on rotation, we have observed that such business-related experiences are often foregone due to time constraints as a result of the focus on gaining clinical competence. In the future, ensuring that students spend time with the business aspects of the community practices during their CBDE should help to address this perceived deficiency in practice management preparation. In light of the increasing burdens of student debt and business pressures associated with dental practice, ${ }^{46}$ adequately addressing such business-related topics is a critical goal not just for our program but for other U.S. dental schools. Importantly, feedback from this survey was consistent with unpublished results of our annual Graduate Survey used to assess components of the predoctoral program.

In our study, planned and actual practice characteristics were generally similar across our study population, suggesting that our pre-graduation data accurately predicted subsequent practice choice. This finding conflicts with a prior study that found disparity between planned and actual dental practice characteristics. ${ }^{33}$ In part, our results may be due to the relatively short duration of practice for East Carolina University SoDM alumni after graduation compared to other studies: the school's first alumni graduated in 2015, and all participants in this study had been practicing for two or fewer years or were still in training. In contrast, that prior study examined graduates who had been practicing for up to 20 years. Future studies examining the practice choices of East Carolina University SoDM graduates over a longer duration will be informative.

Several factors limit the generalizability of our findings. First, our preliminary data describe students and graduates from a single new dental school over a relatively short period of time. The East Carolina University SoDM, established in 2011, had graduated four classes of new dentists at the time of this study (three reported here), many of whom are still in residency programs and may be out of state and planning to return or in state and planning to practice elsewhere. Although we report data from all graduating classes through 2017 as a benchmark for future comparisons, follow-up is needed to determine the duration of the CBDE program on practice characteristics and to assess the relative magnitude of factors influencing these characteristics. This point is particularly important, given that the alumni surveys were distributed to all members of the target population at the same time, so participants from different graduating classes had been in practice for different durations. In addition, the limited number of alumni respondents and design of our data collection instruments precluded linking the pre- to the post-graduation data between individuals; thus, we are unable to comment on changes in practice plans (at the level of the individual study participant) in our preliminary data. Despite these limitations due to the preliminary nature of our data, the consistency of our findings with those from other dental schools using similar CBDE models is encouraging.

Second, the methods used to assess attitudes about the CBDE experience had drawbacks that could potentially affect the interpretation of data. 
Student attitudes were assessed through non-blinded student reflections in the East Carolina University SoDM curriculum; thus, the responses may have been positively biased or failed to reflect the full breadth of student concerns regarding the CBDE experience. Similarly, although the survey was blinded, its anonymous structure did not permit thorough validation of the reported attitudes. Given the consistency of the student and survey data regarding the CBDE experience, however, it is unlikely that either of these methodological factors meaningfully affected the interpretation of our results.

Finally, because of our educational model and study design, we were not able to isolate the specific impact of CBDE versus other education-related factors (e.g., admission/recruitment strategies, nonCBDE didactic methods) on practice characteristics. Future studies pooling data across multiple institutions will be needed to assess the relative contributions of these factors.

Building on this research, we plan to conduct longer term studies assessing practice characteristics and factors influencing practice choice for greater numbers of East Carolina University SoDM graduates, to validate our results with rigorous approaches for tracking and evaluating practice outcomes, and to benchmark our outcomes against those reported nationally in the annual senior survey conducted by the American Dental Education Association (ADEA). ${ }^{1}$ Longitudinal analyses of student practice plans assessed at early or late times during dental training and realized alumni practice characteristics will also be informative for assessing patterns relating to practice choice, as will analyses of student characteristics that predict subsequent interest in a rural or public health career and analyses of the effect of debt amount on practice choice. Finally, national studies pooling data across institutions with similarly structured CBDE programs and admission strategies will assess the relationship between educational model and practice patterns. Documenting improved oral health in the state by a variety of measures will be the ultimate evidence of the impact of this educational model.

\section{Conclusion}

This article documents for the first time the preliminary practice choices of dentists graduating from the East Carolina University SoDM. We demonstrated that the majority of graduates planned to and do practice in the state of North Carolina after graduation, with a substantial proportion practicing in rural areas. Together with positive student and alumni assessments, these data provide preliminary evidence of the effectiveness of the CBDE component of our educational model in addressing the critical shortage of dentists in North Carolina.

\section{Acknowledgments}

This work was supported in part by research seed funding from East Carolina University and the School of Dental Medicine to Dr. Sharon Gordon. The authors thank Annie Fuller for her contributions to the literature review for this article in fulfillment of her program requirements and Dr. Dennis McCunney, Director of the ECU Center for Leadership and Civic Engagement, for contributing to elements of the curriculum in the Community Oral Health Practice course. We also thank Dr. Margaret Wilson and Mr. Lamont Lowery for their assistance in providing data for components of this work. Scientific writing assistance was provided by Melissa Christianson, $\mathrm{PhD}$, in affiliation with Whitsell Innovations, Inc.

\section{Disclosure}

The authors do not have any financial or other competing interests to declare.

\section{REFERENCES}

1. Wanchek T, Cook BJ, Valachovic RW. Annual ADEA survey of dental school seniors: 2017 graduating class. J Dent Educ 2018;82(5):524-39.

2. Voinea-Griffin A, Solomon ES. Dentist shortage: an analysis of dentists, practices, and populations in the underserved areas. J Public Health Dent 2016;76(4):314-9.

3. Vujicic M. Where do dental school graduates end up locating? J Am Dent Assoc 2015;146(10):775-7.

4. Eke PI, Dye BA, Wei L, et al. Update on prevalence of periodontitis in adults in the United States: NHANES 2009 to 2012. J Periodontol 2015;86(5):611-22.

5. McNeil DW, Hayes SE, Randall CL, et al. Depression and rural environment are associated with poor oral health among pregnant women in Northern Appalachia. Behav Modif 2016;40(1-2):325-40.

6. Haden NK, Hendricson WD, Kassebaum DK, et al. Curriculum change in dental education, 2003-09. J Dent Educ 2010;74(5):539-57.

7. Advisory Committee on Training in Primary Care Medicine and Dentistry. Eighth annual report to the Secretary of the U.S. Department of Health and Human Services and to the U.S. Congress: the redesign of primary care with implications for training. Rockville, MD: U.S. Department of Health and Human Services, 2010.

8. Institute of Medicine and National Research Council. Improving access to oral health care for vulnerable and underserved populations. Washington, DC: National Academies Press, 2011. 
9. Commission on Dental Accreditation. Accreditation standards for dental education programs. 2018. At: www. ada.org/ /media/CODA/Files/pde.pdf. Accessed 12 Feb. 2018.

10. Wanchek T, Cook BJ, Anderson EL, Valachovic RW. Annual ADEA survey of dental school seniors: 2014 graduating class. J Dent Educ 2015;79(9):1108-28.

11. Mays KA. Community-based dental education models: an analysis of current practices at U.S. dental schools. J Dent Educ 2016;80(10):1188-95.

12. Nayar P, McFarland K, Lange B, et al. Supervising dentists' perspectives on the effectiveness of communitybased dental education. J Dent Educ 2014;78(8):1139-44.

13. Bean CY, Rowland ML, Soller H, et al. Comparing fourthyear dental student productivity and experiences in a dental school with community-based clinical education. J Dent Educ 2007;71(8):1020-6.

14. Smith M, Lennon MA, Brook AH, Robinson PG. A randomized controlled trial of outreach placement's effect on dental students' clinical confidence. J Dent Educ 2006;70(5):566-70.

15. Smith M, Lennon MA, Brook AH, et al. A randomized controlled trial of the effect of outreach placement on treatment planning by dental students. Br Dent J 2006;Suppl:27-31.

16. McQuistan MR, Kuthy RA, Heller KE, et al. Dentists' comfort in treating underserved populations after participating in community-based clinical experiences as a student. J Dent Educ 2008;72(4):422-30.

17. McFarland KK, Nayar P, Ojha D, et al. Impact of community-based dental education on attainment of ADEA competencies: students' self-ratings. J Dent Educ 2016;80(6):670-6.

18. Davidson PL, Carreon DC, Baumeister SE, et al. Influence of contextual environment and community-based dental education on practice plans of graduating seniors. J Dent Educ 2007;71(3):403-18.

19. Strauss RP, Stein MB, Edwards J, Nies KC. The impact of community-based dental education on students. J Dent Educ 2010;74(10 Suppl):S42-55.

20. Johnson G, Blinkhorn A. Assessment of a dental rural teaching program. Eur J Dent 2012;6(3):235-43.

21. Piskorowski WA, Stenafac SJ, Fitzgerald M, et al. Influence of community-based dental education on dental students' preparation and intent to treat underserved populations. J Dent Educ 2012;76(5):534-9.

22. Altman DS, Alexander JL, Woldt JL, et al. Perceived influence of community oral health curriculum on graduates' dental practice choice and volunteerism. J Dent Educ 2013;77(1):37-42.

23. Johnson G, Blinkhorn A. The influence of a clinical rural placement programme on the work location of new dental graduates from the University of Sydney, NSW, Australia. Eur J Dent Educ 2013;17(4):229-35.

24. Lalloo R, Evans JL, Johnson NW. Dental students' reflections on clinical placement in a rural and indigenous community in Australia. J Dent Educ 2013;77(9):1193-201.

25. Hamershock RA, Rajabiun S, Fox JE, et al. Dental students' HIV/AIDS-related knowledge, attitudes, and intentions: impact of the U.S. Health Resources and Services Administration's community-based dental partnership program. J Dent Educ 2014;78(8):1106-17.
26. Behar-Horenstein LS, Feng X, Roberts KW, et al. Developing dental students' awareness of health care disparities and desire to serve vulnerable populations through service-learning. J Dent Educ 2015;79(10):1189-200.

27. Shannon CK, Price SS, Jackson J. Predicting rural practice and service to indigent patients: survey of dental students before and after rural community rotations. J Dent Educ 2016;80(10):1180-7.

28. DeCastro JE, Matheson PB, Panagakos FS, et al. Alumni perspectives on community-based and traditional curricula. J Dent Educ 2003;67(4):418-26.

29. Kuthy RA, McQuistan MR, Heller KE, et al. Dental students' perceived comfort and future willingness to treat underserved populations: surveys prior to and immediately after extramural experiences. Spec Care Dent 2010;30(6):242-9.

30. Volvovsky M, Vodopyanov D, Inglehart MR. Dental students and faculty members' attitudes towards care for underserved patients and community service: do community-based dental education and voluntary servicelearning matter? J Dent Educ 2014;78(8):1127-38.

31. Robert Wood Johnson Foundation. Pipeline, profession, and practice: community-based dental education. At: www.rwjf.org/content/dam/farm/reports/program results_reports/2013/rwjf69623. Accessed 12 Feb. 2018.

32. Nashleanas BM, McKernan SC, Kuthy RA, Qian F. Career influences among final year dental students who plan to enter private practice. BMC Oral Health 2014;14:18.

33. Smith CS, Ester TV, Inglehart MR. Dental education and care for underserved patients: an analysis of students' intentions and alumni behavior. J Dent Educ 2006;70(4):398-408.

34. Chadwick DG. The East Carolina University School of Dental Medicine's approach to dental workforce education and reaching underserved areas. N C Med J 2012;73(2):108-10.

35. Chadwick DG, Wilson MB, Anderson CF. Shaping oral health care in North Carolina with East Carolina University's community service-learning centers. N C Med J 2014;75(1):36-8.

36. Centers for Disease Control and Prevention, National Center for Health Statistics. Active dentists, by state: United States, selected years 2001-15. 2016. At: www.cdc. gov/nchs/data/hus/2016/086.pdf. Accessed 12 Feb. 2018.

37. Weintraub JA, Burgette JM, Chadwick DG. Educating NC's oral health workforce in an evolving environment. N C Med J 2016;77(2):107-11.

38. University of North Carolina Health Care and School of Medicine Newsroom. Map of NC doctor shortage. At: news.unchealthcare.org/images/portraits/map-of-doctorsin-nc/view. Accessed 23 Feb. 2018.

39. Health Resources and Services Administration. Quick maps: dental health professional shortage areas. 2018 At: datawarehouse.hrsa.gov/Tools/MapToolQuick. aspx?mapName=HPSADC. Accessed 12 Feb. 2018.

40. East Carolina University Brody School of Medicine. Meeting our mission. At: www.ecu.edu/cs-admin/news/ Brody-Graduate-Survey.cfm. Accessed 22 June 2018.

41. Wilson MB, Sedlacek WE, Lowery BL. An approach to using noncognitive variables in dental school admissions. J Dent Educ 2014;78(4):567-74. 
42. Gordon SM, Camargo GA, Mejia GC, Sutherland JN. Use of the dental electronic health record for research: assessing demographic and oral health characteristics data for clinic patients. J Dent Educ 2018;82(12):1249-57.

43. Valachovic RW. Placing dentists where they can do the most good. At: adeachartingprogress.wordpress. com/2018/01/16/placing-dentists-where-they-can-do-themost-good/. Accessed 12 Feb. 2018.

44. North Carolina Department of Commerce. Rural center expands its classification of North Carolina counties. At: www.nccommerce.com/lead/research-publications/ the-lead-feed/artmid/11056/articleid/123/rural-centerexpands-its-classification-of-north-carolina-counties. Accessed 11 Apr. 2018.

45. Federal Office of Rural Health Policy. List of rural counties and designated eligible census tracts in metropolitan counties. At: www.hrsa.gov/sites/default/files/ruralhealth/ resources/forhpeligibleareas.pdf. Accessed 23 Apr. 2018.
46. Badger GR, Fryer CE, Giannini PJ, et al. Helping dental students make informed decisions about private practice employment options in a changing landscape. J Dent Educ 2015;79(12):1396-401.

47. Smith KP, Woldt JL, Cottam WW, Cederberg RA. The Arizona model: a new paradigm for dental schools. J Dent Educ 2011;75(1):3-12.

48. Rohra AK, Piskorowski WA, Inglehart MR. Communitybased dental education and dentists' attitudes and behavior concerning patients from underserved populations. J Dent Educ 2014;78(1):119-30.

49. Deogade SC, Naitam D. Reflective learning in community-based dental education. Educ Health (Abingdon) 2016;29(2):119-23.

50. Major N, McQuistan MR. An exploration of dental students' assumptions about community-based clinical experiences. J Dent Educ 2016;80(3):265-74. 